\title{
Sistem Kendali Kendaraan untuk Keselamatan Aktif: Review Paper
}

\author{
Rina Ristiana ${ }^{1}$, Arief Syaichu Rohman², Ary Setijadi Prihatmanto ${ }^{3}$, Carmadi Machbub ${ }^{4}$ \\ ${ }^{l}$ UPT. Balai Pengembangan Instrumentasi - LIPI \\ Jl. Sangkuriang Gedung 30 Kompleks LIPI Bandung \\ ${ }^{2,3,4}$ Sekolah Teknik Elektro dan Informatika - ITB \\ Jl. Ganesha No. 10 Bandung \\ Email : ${ }^{1}$ rina005@lipi.go.id, ${ }^{2}$ arief@1skk.ee.itb.ac.id, ${ }^{3}$ ary.setijadi@gmail.com, \\ ${ }^{4}$ carmadi@1skk.ee.itb.ac.id
}

\begin{abstract}
Abstrak - Telah dilakukan telaah makalah mengenai sistem kendali untuk meningkatkan keselamatan berkendaraan. Sistem kendali ditentukan pada low level yang berfungsi untuk menjaga kestabilan kendaraan. Kendaraan dijelaskan dalam bentuk dinamika dan sistem pemindah daya. Permasalahan sistem kendali pada mobil listrik terletak pada ketersediaan energi baterai yang mempengaruhi kestabilan kendaraan, sehingga perlu optimisasi efisiensi energi.
\end{abstract}

Kata kunci: sistem keselamatan aktif, kestabilan kendaraan, optimasi efiseinsi energi

\section{Pendahuluan}

Tahun 2011, Ferdinando dari Bosch Automotive Product (Suzhou) Co. Ltd melakukan survei terhadap pengguna mobil yang berasal dari 7 negara Eropa (Inggris, Belanda, Belgia, Jerman, Perancis, Itali dan Spayol) mengenai hal apa saja yang harus diperhatikan dalam memilih kriteria sebuah mobil. Hasil survei menunjukkan bahwa sistem keselamatan (safety) menjadi faktor penting dalam memilih sebuah mobil [3].

Sistem keselamatan pada kendaraan terdiri dari sistem keselamatan pasif (passive safety) dan sistem keselamatan aktif (active safety). Sistem keselamatan pasif adalah suatu sistem yang berfungsi untuk meminimalkan resiko cedera serius pada pengemudi maupun penumpang saat terjadi kecelakaan. Contoh sistem keselamatan pasif seperti sabuk pengaman (seat belt), kantong udara (airbag), dan sebagainya. Sistem keselamatan aktif adalah suatu sistem yang berfungsi untuk membantu pengemudi meminimalkan terjadinya resiko tabrakan. Sistem keselamatan aktif merupakan piranti elektronik yang mampu mendeteksi kondisi aman dan kondisi tidak aman (berpotensi terjadi kecelakaan). Contoh keselamatan aktif seperti kendali rem (Anti-lock breaking system-ABS) berfungsi mendeteksi kemungkinan penguncian roda saat terjadi pengereman mendadak, kendali traksi (traction control system-TCS) berfungsi untuk pengendalian tenaga penggerak, dan electronic control system (ECS) berfungsi untuk meningkatkan stabilitas kendaraan saat berjalan [5].

Saat ini industri otomotif mengembangkan teknologi keselamatan aktif yang disebut driver assistance system (kendaraan pintar). Teknologi ini dibangun dari dua sistem besar. Yang pertama sistem yang memiliki fungsi otomatis membaca marka jalan yang mengatur kendaraan berada dalam posisi aman tanpa keluar dari lajur seharusnya. Sistem ini dilengkapi dengan kamera kendaraan, sensor akselerasi serta GPS untuk komunikasi dan navigasi. Yang kedua adalah sebuah sistem yang mampu mendeteksi jarak kendaraan atau objek lainnya secara otomatis, sehingga pengaturan jarak antar kendaraan atau objek lainnya bisa terjaga. Tujuan pengembangan sistem pintar ini adalah untuk mengendalikan akselerasi kendaraan secara konstan sehingga

TELKA, Vol.3, No.1, Mei 2017, pp. 1 12

ISSN (e): 2540-9123

ISSN (p): 2502-1982 
tingkat konsumsi bahan bakar kendaraan akan menurun, serta membantu menurunkan tingkat kemacetan.

Ada dua faktor yang menjadi tujuan dari setiap pengembangan teknologi otomotif yaitu mempermudah pengendalian kendaraan dan meningkatkan keselamatan berkendara. Dalam prakteknya, sistem keselamatan tidak akan melakukan fungsinya dengan baik, apabila tidak ditunjang dengan sistem kendali yang tepat. Makalah ini memuat penelusuran mengenai sejauh mana penerapan teknologi kendali saat ini untuk meningkatkan keselamatan aktif pada kendaraan.

\section{Dinamika Kendaraan}

Umumnya kendaraan memiliki karakteristik yang terdiri dari performance, handling dan ride. Performance adalah kemampuan kendaraan untuk melakukan akselerasi, deselerasi dan penghindaran objek. Handling adalah kemampuan kendaraan merespon interaksi dari pengemudi. Ride adalah kemampuan kendaraan berinteraksi dengan lingkungannya, misalnya rute jalan, tipe permukaan jalan, kondisi trafik dan sebagainya [10].

Dengan karakteristik tersebut, kendaraan dapat melakukan pergerakan-pergerakan yang digambarkan dalam sistem koordinat (Gambar 1). Sistem koordinat kendaraan memiliki tiga sumbu (x, y, z) dengan titik pusat sumbu pada titik gravitasi (center of gravitasi). Pergerakan searah sumbu $x$ disebut gerak longitudinal (maju-mundur) dan gerak roll. Pergerakan searah sumbu y disebut gerak lateral (belok kanan-kiri) dan gerak yaw. Pergerakan searah sumbu z disebut gerak vertikal (berosilasi ke atas-ke bawah) dan gerak pitch. $[4,19]$

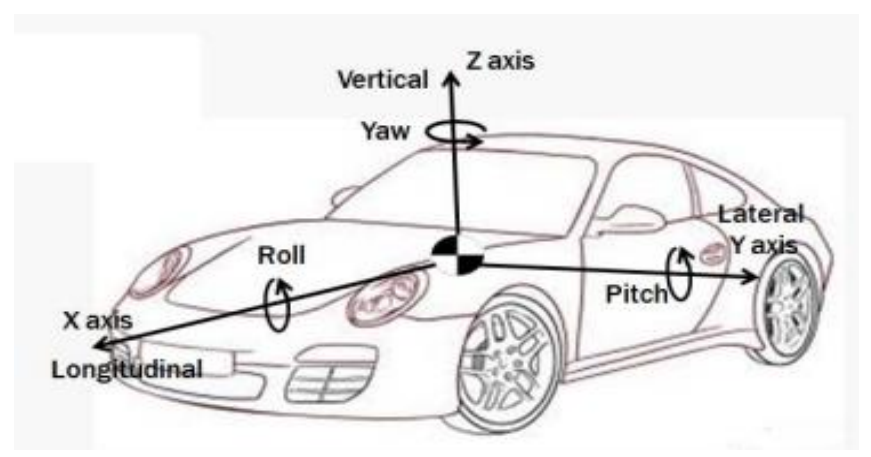

Gambar 1. Sistem Koordinat Kendaraan [4]

Pergerakan kendaraan diilustrasikan dalam dinamika seperti yang dapat dilihat pada (Gambar 2). Dinamika kendaraan diklasifikasikan menjadi tiga bagian, yakni dinamika longitudinal, dinamika lateral dan dinamika vertikal. Pengemudi memegang peranan penting dalam kendali secara manual atas masukan sistem dinamika. Masukan terdiri dari pedal rem (brake), pedal gas (acceleration) dan kemudi (steering). Pergerakan kendaraan dipengaruhi oleh gangguan (disturbance) berupa gaya lawan angin, variasi kondisi permukaan jalan dan ketidakpastian gerakan wahana. 


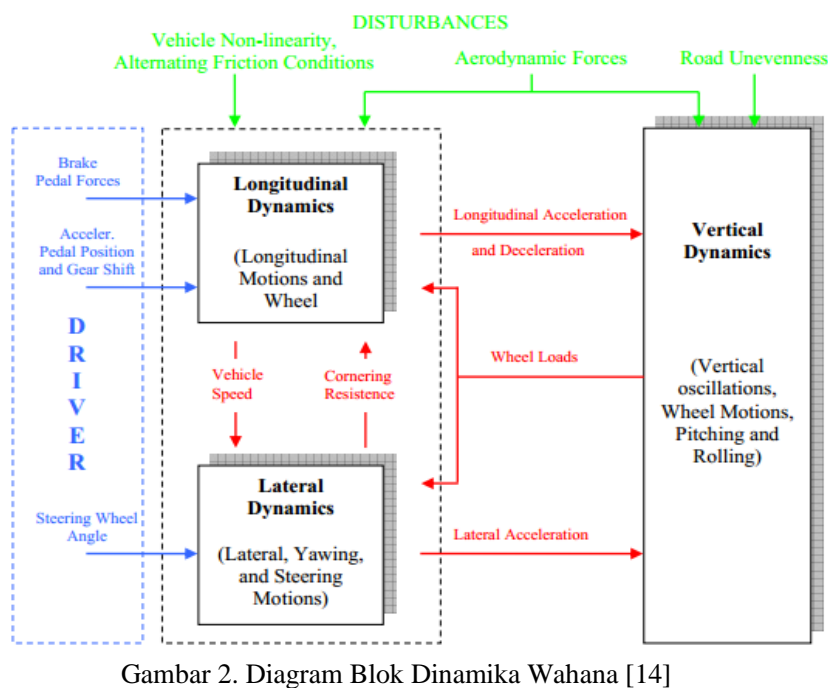

\subsection{Dinamika Longitudinal}

Saat kendaraan bergerak arah longitudinal terdapat beberapa gaya yang bekerja pada kendaraan. Sesuai hukum kedua Newton jumlah gaya yang bekerja pada arah translasi benda tersebut sama dengan massa dikalikan percepatan benda tersebut. Sehingga gaya longitudinal kendaraan dapat dituliskan berikut;

$$
m \ddot{x}=F_{x}-F_{\text {aero }}-F_{R x}-F_{g}-F_{C R}
$$

Dengan, $\mathrm{m}$ adalah massa, $\ddot{x}$ untuk percepatan longitudinal, $\mathrm{F}_{\mathrm{x}}$ adalah gaya longitudinal ban, $\mathrm{F}_{\text {aero }}$ merupakan gaya lawan angin $\left(F_{\text {aero }}=1 / 2 \rho C_{d} A_{f}\left(V_{x}+V_{\text {wind }}\right)^{2}\right), \mathrm{F}_{\mathrm{Rx}}$ adalah gaya hambat roll $\left(F_{R x}=C_{R x}\left(F_{z f}+F_{z r}\right)\right), \mathrm{F}_{\mathrm{g}}$ adalah gaya gravitasi $\left(F_{g}=m g \sin \theta\right)$ dan $\mathrm{F}_{\mathrm{CR}}$ adalah gaya hambat belok $\left(F_{C R}=m V_{y} \dot{\psi}\right)[4,18]$.

\subsection{Dinamika Lateral} berikut;

Gaya-gaya yang bekerja pada kendaraan searah sumbu lateral dapat dituliskan sebagai

$$
m \ddot{y}=F_{y}+F_{\text {bank }}+F_{C P}
$$

Dengan, $\mathrm{m}$ adalah massa, $\ddot{y}$ adalah percepatan lateral, $\mathrm{F}_{\mathrm{y}}$ adalah gaya lateral ban, $\mathrm{F}_{\mathrm{bank}}$ adalah gaya sudut jalan $\left(F_{\text {bank }}=m g \sin (\varphi)\right)$, dan $F_{C P}$ adalah gaya sentripetal $\left(F_{C P}=m V_{x} \dot{\psi}\right)$ $[4,18]$.

\subsection{Dinamika Roda}

Roda memiliki tiga sumbu (X, Y, Z) dengan titik pusat terlatak pada titik pertemuan ban dengan jalan (contact path). Sumbu X merupakan perpotongan antara permukaan jalan dengan ban terhadap sumbu tegak menuju ke arah depan, sumbu y merupakan perpotongan pusat sumbu antara permukaan jalan terhadap sumbu tegak menuju ke arah samping, sedangkan sumbu $\mathrm{z}$ merupakan perpotongan pusat sumbu antara permukaan jalan terhadap sumbu tegak ke atas. Sedangkan arah pergerakan roda kendaraan terhadap sumbunya atau disebut dengan momen inersia roda meliputi $\mathrm{M}_{\mathrm{x}}$ (overturning moment), $\mathrm{M}_{\mathrm{y}}$ (rolling resistance moment) dan $\mathrm{M}_{\mathrm{z}}$ (aligning moment) [17]. 

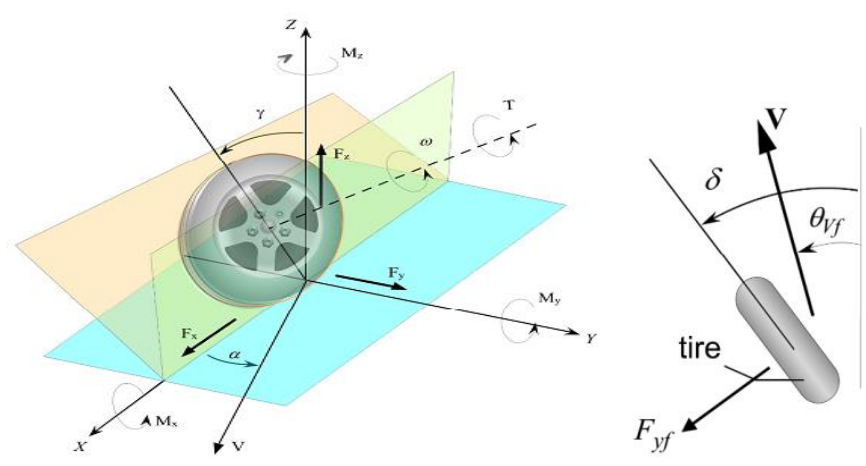

Gambar 3. Dinamika Roda [19]

Gaya yang bekerja pada ban kendaraan meliputi gaya longitudinal ban $\left(\mathrm{F}_{\mathrm{x}}\right)$, gaya lateral ban $\left(\mathrm{F}_{\mathrm{y}}\right)$ dan gaya normal ban $\left(\mathrm{F}_{\mathrm{z}}\right)$. Gaya longitudinal ban dipengaruhi oleh rasio slip roda $(\sigma)$, dan ditulis dengan persamaan berikut :

$$
F_{x}=C_{\sigma} \sigma_{x}
$$

Dengan $\mathrm{C}_{\sigma}$ adalah koefisien kekakuan longitudinal ban dan $\sigma_{\mathrm{x}}$ adalah rasio slip roda. Rasio slip roda memiliki batasan operasional sebagai berikut :

$$
\begin{gathered}
\sigma_{x}=\frac{r_{w} \omega_{w}-V_{x}}{V_{x}} \text { selama pengereman } \\
\sigma_{x}=\frac{r_{w} \omega_{w}-V_{x}}{r_{w} \omega_{w}} \text { selama akselerasi }
\end{gathered}
$$

Dengan $\mathrm{r}_{\mathrm{w}}$ adalah panjang jari-jari roda, $\omega_{\mathrm{w}}$ adalah kecepatan roda dan $\mathrm{v}_{\mathrm{x}}$ adalah kecepatan kendaraan. Selanjutnya gaya lateral ban dipengaruhi oleh sudut slip $(\alpha)$, dan persamaannya ditulis sebagai berikut :

$$
F_{y}=C_{\alpha} \alpha_{y}
$$

Dengan $\mathrm{F}_{\mathrm{y}}$ adalah gaya lateral ban, dan $\mathrm{C}_{\alpha}$ merupakan koefisien kekakuan berbelok ban. Sudut slip roda depan dan roda belakang berbeda, dimana sudut slip ini dipengaruhi oleh sudut kemudi $(\delta)$, dan sudut kecepatan ban depan $\left(\theta_{\mathrm{vf}}\right)$. Persamaan sudut slip roda dapat ditulis sebagai berikut :

$$
\begin{array}{ll}
\text { Depan } & : \alpha_{f}=\delta-\theta_{V f} \text { dengan } \theta_{V f}=\frac{V_{y}+l_{f} \dot{\psi}}{V_{x}} \\
\text { Belakang }: & \alpha_{r}=-\theta_{V r} \text { dengan } \theta_{V r}=\frac{V_{y}-l_{r} \dot{\psi}}{V_{x}}
\end{array}
$$

Dengan $\mathrm{v}_{\mathrm{y}}$ adalah kecepatan lateral, $\dot{\psi}$ adalah yaw rate, $\mathrm{l}_{\mathrm{f}}$ adalah panjang kendaraan dari depan ke titik gravitasi dan $l_{\mathrm{r}}$ adalah panjang kendaraan dari titik gravitasi ke belakang. Gaya normal ban adalah gaya berat ban terhadap gravitasi bumi atau gaya-gaya yang bekerja searah sumbu z. Persamaan gaya normal ban depan sebagai berikut :

$$
F_{z f}=F_{g} h+\frac{m g l_{r}}{2\left(l_{r}+l_{f}\right)}-\frac{m \ddot{x} h}{2\left(l_{r}+l_{f}\right)}-\frac{F_{a e r o} h}{4 l_{s}}
$$

Persamaan gaya normal ban belakang sebagai berikut :

$$
F_{z r l}=-F_{g} h-\frac{m g l_{r}}{2\left(l_{r}+l_{f}\right)}+\frac{m \ddot{x} h}{2\left(l_{r}-l_{f}\right)}+\frac{F_{\text {aero }} h}{4 l_{s}}
$$

Dengan $\mathrm{F}_{\mathrm{g}}$ sama dengan gaya gravitasi, $\mathrm{m}$ adalah massa, $\mathrm{g}$ adalah percepatan gravitasi, $\mathrm{h}$ adalah tinggi jarak titik gravitasi ke permukaan tanah, dan $1_{\mathrm{s}}$ adalah lebar badan kendaraan. 


\section{Pemindahan Daya}

Pemindah daya (powertrain) berfungsi untuk memindahkan tenaga yang bersumber dari mesin ke penggerak roda sehingga kendaraan dapat berjalan. Berdasarkan peletakan mesin dan penggerak rodanya, pemindah daya dikelompokkan menjadi emat tipe. Pertama, Front engine Front drive (FF) adalah letak mesin berada di bagian depan mobil dan roda depan digerakan oleh mesin. Jadi roda belakang hanya berputar saja tidak mendapat tenaga dari mesin. Kedua, Front engine Rear drive (FR) adalah letak mesin berada di bagian depan mobil, dan roda belakang digerakan oleh mesin. Ketiga, Rear engine Rear drive (RR) adalah letak mesin berada dibagian belakang mobil dan roda belakang yang digerakan oleh mesin. Keempat, Four Wheel Drive (4WD) maksudnya roda belakang dan roda depan sama-sama mendapat tenaga dari mesin. Tipe pemindah daya FF dan FR dapat dilihat pada gambar 4. Skema aliran tenaga tipe FR :

\section{Mesin $\rightarrow$ Kopling $\rightarrow$ Transmisi $\rightarrow$ Propeller $\rightarrow$ Gardan $\rightarrow$ Penggerak roda}

Mesin (engine) adalah sumber utama tenaga penggerak. Daya mesin $\left(\mathrm{P}_{\mathrm{e}}\right)$ merupakan perkalian kecepatan mesin $\left(\omega_{\mathrm{e}}\right)$ dengan toka mesin $\left(\mathrm{T}_{\mathrm{e}}\right)$, ditulis persamaannya ;

$$
P_{e}=T_{e} \omega_{e}
$$

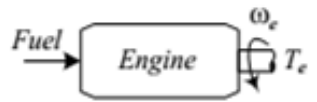

Kopling (clutch) berfungsi sebagai pemutus dan penghubung tenaga dari mesin ke transmisi. Transmisi berfungsi untuk mengatur tingkat kecepatan saat kendaraan maju, netral dan mundur. Persamaan kecepatan penggerak gigi $\left(\omega_{\mathrm{d}}\right)$ dan torka gigi $\left(\mathrm{T}_{\mathrm{d}}\right)$ dituliskan sebagai berikut; (dengan $\mathrm{n}_{\mathrm{i}}$ adalah jumlah rasio gigi dan $\eta_{\mathrm{g}}$ adalah efisiensi gigi).

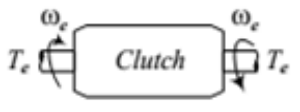

$\omega_{d}=\frac{\omega_{e}}{n_{i}} \quad$ dan

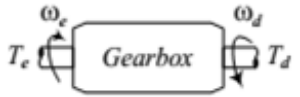

$T_{d}=\eta_{g} n_{i} T_{e}$

Propeller berfungsi untuk meneruskan tenaga dan putaran dari keluaran transmisi ke gardan. Gardan (differential) berfungsi untuk mengubah sumbu putar propeller sebesar 90 derajat (dari arah memanjang menjadi melintang) dan mendistribusikan putaran mesin ke poros roda kiri dan kanan saat kendaraan berbelok. Persamaan kecepatan roda $\left(\omega_{\mathrm{w}}\right)$ dan persamaan torka roda $\left(\mathrm{T}_{\mathrm{w}}\right)$ ditulis sedbagai berikut; (dengan $\mathrm{n}_{\mathrm{d}}$ adalah rasio gardan dan $\eta_{\mathrm{d}}$ adalah efisiensi gardan).

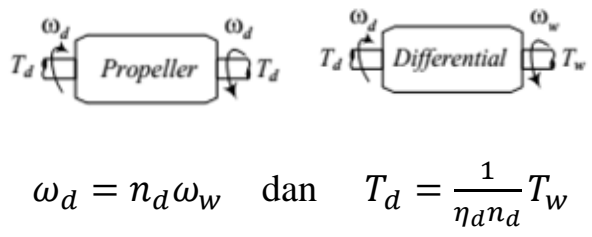

Poros (axle) roda berfungsi meneruskan torka ke roda sehingga roda berputar. Terdapat gaya longitudinal ban $\left(\mathrm{F}_{\mathrm{x}}\right)$ merupakan perbandingan torka roda terhadap jarak jari-jari roda $\left(\mathrm{r}_{\mathrm{w}}\right)$ dan kecepatan longitudinal atau kecepatan kendaraan $\left(\mathrm{V}_{\mathrm{x}}\right)$ distulis persamaanya sebagai berikut;

$$
\begin{aligned}
& F_{x}=\frac{T_{w}}{r_{w}} \text { dan } V_{x}=\omega_{w} r_{w}
\end{aligned}
$$

Persamaan penggerak roda belakang menjadi; 


$$
\begin{gathered}
I_{w} \dot{\omega}_{w}=T_{d}-T_{b}-r_{w} F_{x} \\
T_{b}=A_{w} \mu_{b} R_{b} P_{b}
\end{gathered}
$$

Torki rem $\left(T_{b}\right)$ merupakan perkalian antara luas rem roda $\left(A_{w}\right)$, koefisien gesek rem $\left(\mu_{b}\right)$, radius rem $\left(\mathrm{R}_{\mathrm{b}}\right)$ dan tekanan rem roda $\left(\mathrm{P}_{\mathrm{b}}\right)$.

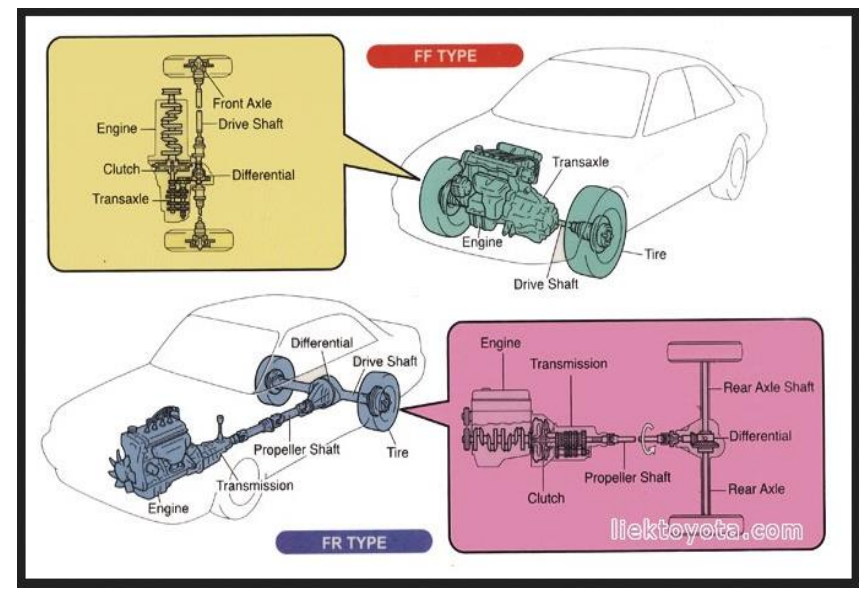

Gambar 4. Pemindah Daya Tipe FF dan FR [10]

\section{Sistem Kendali}

Sistem kendali kendaraan diklasifikasikan dalam tiga level, yaitu low-level untuk menjaga kestabilan kendaraan, medium-level untuk kendali pergerakan kendaraan dan high level untuk manajemen trafik kendaraan. Kendali low level dibagi lagi menjadi kendali low level dasar dan kendali low level lanjut. Pada kendali low level dasar, sistem kendali ini digunakan untuk mengendalikan sebuah subsistem saja, contohnya kendali rem berfungsi hanya untuk mengendalikan bagian rem, kendali motor berfungsi hanya untuk mengendalikan motor saja, dan seterusnya. Sedangkan kendali low level lanjut merupakan suatu kendali yang mengatur beberapa subsistem dasar agar dapat saling berkoordinasi, saling berinteraksi dan saling berkomunikasi. Contohnya mengatur kecepatan kendaraan. Dalam mengatur kecepatan kendaraan harus memperhatikan beberapa parameter seperti berapa persen kondisi rem, berapa akselerasinya dan bagaimana arah kemudinya kemudinya. [13]

Tabel 1. Klasifikasi Sistem Kendali Kendaraan

\begin{tabular}{|l|l|}
\multicolumn{2}{c|}{ Tabel 1. Klasifikasi Sistem Kendali Kendaraan } \\
\begin{tabular}{|l|l|}
\hline Low-Level \\
Menjaga Kestabilan Wahana (stability)
\end{tabular} \\
\hline Dasar & $\begin{array}{l}\text { Kendali motor } \\
\text { Kendali transmisi } \\
\text { Kendali steering } \\
\text { Kendali pengereman } \\
\text { Kendali daya }\end{array}$ \\
\hline Lanjut & $\begin{array}{l}\text { Electronic stability control (ESC) } \\
\text { Direct Yawing control (DYC) } \\
\text { Rolling Stability control (RSC) } \\
\text { Pitching Stability control (PSC) } \\
\text { Bounching Stability Control (BSC) }\end{array}$ \\
\hline Medium-Level \\
Kendali Pergerakan Wahana (tracking)
\end{tabular}




\begin{tabular}{|l|l|}
\hline $\begin{array}{l}\text { Kendaraan pintar } \\
\text { (driver assistant) }\end{array}$ & $\begin{array}{l}\text { Kendali kecepatan, kendali jarak, kendali } \\
\text { menghindari tabrakan }\end{array}$ \\
\hline High-Level & \\
Kendali Traffik (intelligent) \\
Pelayanan komunikasi, sarana informasi jarak jauh, navigasi, peta rute
\end{tabular}

Kendali low level lanjut berfungsi untuk menjaga kestabilan kendaraan karena pergerakannya. Kendali medium level merupakan sistem kendali level otomatisasi kendaraan dengan diperkenalkannya driver assistance atau kendaraan pintar. Kendaraan pintar ini dapat mendeteksi kecepatan, mendeteksi jarak, menghindari objek, melakukan percepatan atau perlambatan, semua hal ini dilakukan secara otomatis tanpa bantuan pengemudi.

Kendali high level adalah sistem kendali yang dirancang untuk memberikan sarana tambahan bagi kendaraan. Seperti dibangun jaringan internet, cyber dan GPS untuk sarana pelayanan komunikasi antar kendaraan. Tersedianya big data untuk mendiagnosa kondisi trafik lalulintas, update peta, dan menentukan rute jalan.

Makalah ini menyajikan penelusuran sistem kendali kendaraan low level khususnya bagaimana kendali dapat menjaga kestabilan kendaraan. Jika dilihat dari sifatnya, kestabilan kendaraan dapat dibedakan menjadi dua macam, yakni kestabilan statis dan kestabilan dinamis. Kestabilan statis adalah suatu kondisi dimana kendaraan dalam keadaan diam. Sedangkan kestabilan dinamis adalah suatu kondisi dimana kendaraan melakukan pergerakan, diantaranya bergerak maju atau mundur (gerak longitudinal), berbelok ke kiri dan ke kanan (gerak lateral dan yawing), bergerak menukik (gerak pitching), bergerak miring kesamping kanan dan kiri (gerak rolling) dan berosilasi keatas dan kebawah (gerak bouncing).

Faktor yang mempengaruhi kestabilan kendaraan adalah faktor internal dan faktor eksternal. Faktor internal tergantung dari karakteristik kendaraan, kualitas peralatan, dan kondisi komponen kendaraan. Sedangkan faktor eksternal tergantung dari cuaca, kondisi jalan, dan tingkat kualitas pengemudi.

Dalam teori kestabilan dikenal dengan istilah kestabilan awal yang ditentukan oleh tiga titik pada kendaraan, diantaranya ;

\subsection{Titik $\mathbf{G}$}

Titik $\mathrm{G}$ adalah titik gravitasi atau centre of grafity (COG), merupakan titik tangkap dari semua gaya-gaya yang menekan atau bekerja ke bawah terhadap bumi, seperti dapat dilihat pada gambar 5. Letak titik $\mathrm{G}$ dapat diketahui dengan meninjau berat bobot kendaraan, dimana jika berat bobot kendaran semakin bertambah maka makin tinggilah letak titik G-nya.

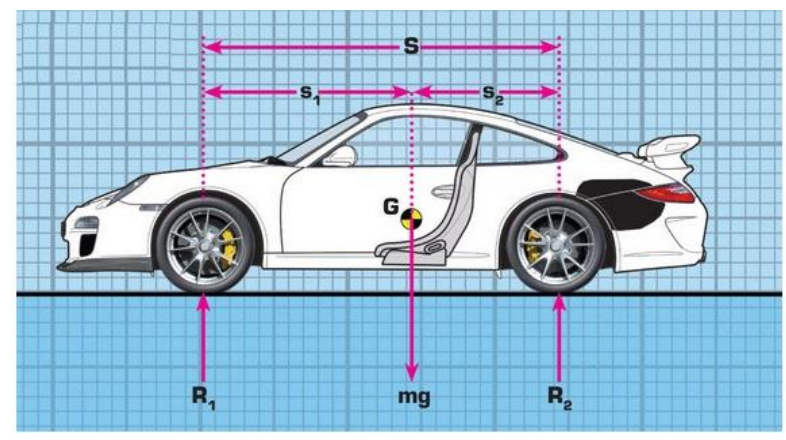

Gambar 5. Letak titik G

\subsection{Titik B}

Titik B merupakan titik tangkap dari kemiringan resultan yang menekan tegak kearah wahana. Titik B bukanlah suatu titik yang tetap, namun akan berpindah-pindah oleh adanya perubahan resultan gaya dari kendaraan. Dalam kestabilan titik B inilah yang menyebabkan kendaraan mampu untuk tegak kembali setelah mengalami tanggapan. 


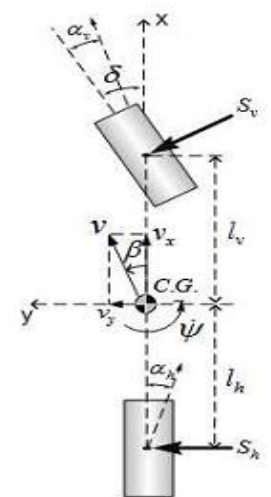

a) Pergerakan Yaw

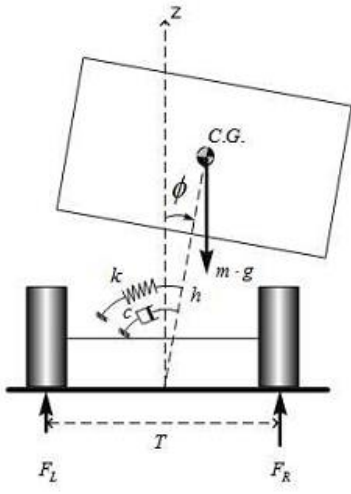

b) Pergerakan Roll

Gambar 6. Letak Titik B

Dari gambar 6 dapat dilihat bahwa saat wahana melakukan pergerakan yaw terdapat resultan kemiringan akibat adanya resultan sudut sideslip $(\beta)$ terhadap sumbu longitudinal yang berpusat sumbu pada titik G. Sedangkan saat pergerakan roll terjadi resultan sudut rolling $(\phi)$ akibat perubahan titik $\mathrm{G}$ terhadap sumbu vertikal wahana.

\subsection{Titik $M$}

Titik M merupakan sebuah titik semu dan batas dimana titik $G$ tidak boleh melewati diatasnya (Gambar 7). Titik $M$ tergantung bentuk badan wahana yang memiliki lebar dan tinggi, sehingga jika tinggi kendaraan bertambah maka titik $\mathrm{M}$ bertambah tingginya dan akan menambah pengaruh terhadap kestabilan.

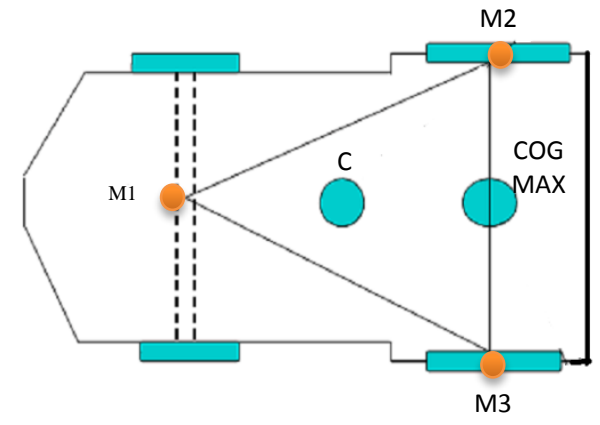

Gambar 7. Letak Titik M

Pada prinsipnya, keadaan kestabilan terdiri dari tiga macam, yaitu, Kestabilan positif (stable equilibrium), Suatu keadaan dimana titik $G$ berada diatas titik $M$ sehingga sebuah wahana memiliki kestabilan mantap/kokoh sewaktu terjadi tanggapan dari luar, saat tanggapan itu hilang akan kembali ke posisi semula. Kestabilan netral (neutral equilibrium), Suatu keadaan dimana titik $\mathrm{G}$ dan titik $\mathrm{M}$ berhimpit, maka yaw momen yang memiliki kestabilan netral sama dengan nol. Dan Kestabilan negatif (stable equlibrium), Suatu keadaan kestabilan dimana titik G berada diatas titik M, sehingga kendaraan memiliki kestabilan negatif sewaktu wahana mendapatkan tanggapan. 


\section{Telaah Makalah}

Dalam makalah ini akan menelaah beberapa makalah mengenai sistem kendali kendaraan khususnya menjaga kestabilan kendaraan, disajikan dalam tabel 2.

Tabel 2. Telaah Makalah

\begin{tabular}{|c|c|c|}
\hline \multirow[t]{2}{*}{1} & $\begin{array}{l}\text { Penulis, } \\
\text { Tahun }\end{array}$ & $\begin{array}{l}\text { Weisong, } 2010 \text { [23], Andrew, } 2013 \text { [1] } \\
\text { John, } 2010 \text { [9] }\end{array}$ \\
\hline & Yang dibahas & Keselamatan aktif kendaraan \\
\hline & Metoda & $\begin{array}{l}\text { - Mengamati koefisien gesekan dan kekakuan ban } \\
\text { dengan kendali kalman filter } \\
\text { - penerapan model predictive control untuk } \\
\text { mengoptimalkan steering dan rem, dan estimasi } \\
\text { perilaku pengemudi dengan swicthing,, pengaruh } \\
\text { ketidak pastian lingkungan } \\
\text { - Algoritma evaluasi efek internal dan eksternal yang } \\
\text { berpotensi pada keselamatan aktif berkendara }\end{array}$ \\
\hline \multirow[t]{3}{*}{2} & $\begin{array}{l}\text { Penulis, } \\
\text { Tahun }\end{array}$ & $\begin{array}{l}\text { Wu Xinye, } 2010 \text { [25], Sangoh, } 2011 \text { [19] } \\
\text { Duo Zhang, } 2013 \text { [2], Hu Ying, } 2014 \text { [7] } \\
\text { Nigam, } 2014 \text { [16], Michael, } 2014 \text { [15] } \\
\text { Shinsuke, } 2008 \text { [20], Jia, } 2011 \text { [8], } \\
\text { Azman, } 2014 \text { [12] }\end{array}$ \\
\hline & Yang dibahas & $\begin{array}{l}\text { Optimatimasi kestabilan roll, yaw,pitch dan bounc } \\
\text { Meningkatkan stabilitas dan manuver }\end{array}$ \\
\hline & Metoda & $\begin{array}{l}\text { Optimalisasi struktur kendaraan, meningkatkan } \\
\text { kestabilan } \\
\text { Perbandingan strategi efektif pengendalian yaw } \\
\text { Meningkatkan stabilitas pada kondisi ekstrim dengan } \\
\text { kecepatan tinggi. } \\
\text { Meningkatkan respon dinamika vertikal pada suspensi } \\
\text { aktif dan semi aktif }\end{array}$ \\
\hline \multirow[t]{3}{*}{3} & $\begin{array}{l}\text { Penulis, } \\
\text { Tahun }\end{array}$ & Tong, 2010 [22] \\
\hline & Yang dibahas & $\begin{array}{l}\text { Desain kendali steering dan pengereman sebagai strategi } \\
\text { keselamatan aktif }\end{array}$ \\
\hline & Metoda & $\begin{array}{l}\text { Membuat hardware in the loop (HIL) dan rapid control } \\
\text { prototype (RCP) dengan pendekatan parameter dinamika } \\
\text { kendaraan. Menggunakan kalman filter untuk kendali } \\
\text { pengereman yang dipadukan dengan chasis aktif }\end{array}$ \\
\hline \multirow[t]{3}{*}{4} & $\begin{array}{l}\text { Penulis, } \\
\text { Tahun }\end{array}$ & Hirosi, 2012 [6], Murphy, 2001 [21] \\
\hline & Yang dibahas & $\begin{array}{l}\text { Keselamatan untuk jarak tempuh per charge } \\
\text { Pengendalian gerakan kendaraan }\end{array}$ \\
\hline & Metoda & $\begin{array}{l}\text { Meningkatkan kisaran pada jalan menikung } \\
\text { Pendekatan disipasi daya dengan memodelkan } \\
\text { persamaan over constraind roda }\end{array}$ \\
\hline
\end{tabular}

\section{Permasalahan dan Peluang Penelitian}

\subsection{Permasalahan-permasalahan}

Dari telaah makalah dapat ditarik beberapa permasalahan yang membutuhkan konsentrasi untuk memberikan solusi atas permasalahan mengatasi kestabilan wahana. Berikut beberapa permasalahan bagi wahana adalah ; 
- Optimasi gerak

Dalam melakukan pergerakannya, kendaraan akan selalu bergantung pada pengereman, steering dan distribusi torki, namun keakuratan pergerakan masih belum efektif. Hal ini disebabkan belum tersedianya nilai constrain yang harus di optimasi.

- Optimasi arah perubahan pergerakan

Saat kendaraan melakukan perubahan arah, pengendalian sudur sideslip dan yaw rate masih belum efektif.

- Optimasi Efisiensi Energi

Meskipun efektif meningkatkan jarak tempuh per charge, namun dapat berpotensi menurunkan kestabilan kendaraan karena perbedaan kekuatan penggerak roda yang dihasilkan antara kiri kanan atau depan belakang.

- Optimasi titik berat

Saat kendaraan statis maka titik berat-nya berhimpitan dengan titik gravitasi. Namun saat ada pergerakan rolling (miring samping), pitching (menukik ke depan dan belakang) dan bouncing (berosilasi ke atas dan ke bawah), maka titik berat wahana berubah ubah dan mempengaruhi kestabilan, sehingga ada kemungkinan wahana tidak stabil atau dapat berguling guling.

\subsection{Peluang Penelitian}

Kendaraan berbahan bakar minyak akan memberikan sumber energi yang statis terhadap gerak kendaraan. Maksudnya walaupun persediaan bahan bakar penuh, setengah atau tinggal sedikit tetap menghasilkan gaya yang sama, terkecuali jika bahan bakar habis sama sekali maka mesin akan mati. Sedangkan pada mobil listrik, sumber energi yang tersimpan dalam baterai terbatas atau dinamis, maka akan berpengaruh terhadap pergerakan kendaraan dan menjaga kestabilan menjadi hal penting.

Beberapa peluang penelitian yang dapat dilakukan untuk mengatasi permasalahan yang khas untuk mobil listrik adalah;

- Terbatasnya ketersediaan energi mempengaruhi pergerakan kendaraan khususnya mobil listrik

- Bagaimana cara efisiensi energi optimum yang digunakan untuk mengendalikan kestabilan kendaraan

- Menemukan berbagai constrain yang memiliki dampak dominan terhadap kestabilan kendaraan

\section{Kesimpulan}

Sistem keselamatan aktif kendaraan adalah salah satu faktor penting dalam memilih kriteria kendaraan. Kendaraan memiliki karakteristik dan kemampuan gerak yang dapat diilustrasikan dalam dinamika kendaraan. Sistem kendali kendaraan dirancang untuk menjaga kestabilan kendaraan dan mengendalikan arah pergerakan kendaraan (tracking). Makalah ini memuat penelusuran sistem kendali low level khususnya bagaimana kendali menjaga kestabilan kendaraan. Dari hasil telaah didapatkan beberapa permasalahan sistem kendali untuk menjaga kestabilan kendaraan. Hal ini merupakan peluang untuk dilakukan penelitian selanjutnya yang di fokuskan pada efisiensi energi optimum untuk menjaga kestabilan mobil listrik. Langkah-langkah yang perlu diambil diantaranya identifikasi untuk menemukan berbagai constraint mobil listrik yang membatasi kinerja dan kestabilan. Selanjutnya memilih mana yang memiliki pengaruh dominan sehingga layak diperhitungkan dalam sistem kendali karena ketersediaan energi baterai:

\section{Daftar Pustaka}

[1] Andrwe Gray, M. Ali, Yiqi Gao, J. Karl and Francesco Borelli, "A Unified Approach to Threat Assessment and Control for Automotive Active Safety", IEEE Transaction on Intelligent Transportation Systems, Vol. 14, No. 3, September 2013. 
[2] Duo Zang, Guohai Liu, dkk “ Active Safety Neural Network Inverse Decoupling Control for Multi Wheel Independently Driven Electric Vehicles". IEEE, 2013.

[3] Ferdinando S., "Bosch Active Safety Survey China”, Chassis Systems Control China, Bosch Automotive Products (Suzhou) Co. Ltd, 2011.

[4] Gillespie T. D., "Fundamentals of Vehicle Dynamics", Society of Automotive Engineers, Inc, 1992.

[5] Hasan A., Mehran S., Bagher, "Lateral Stabilization of A Four Wheel Independent Drive Electric Vehicle on Slippery Roads", Elsevier, 2014, http://dx.doi.org/10.1016/j.mechatronics.2014.08.006.

[6] Hiroshi Fujimoto and Hayato Sumiya, "Advanced Safety Range Extension Control System for Electric Vehicle with Front and Rear Active Steering and Left and Right Force Distribution", IEEE/ASME International Conference on Advanced Intelligent Mechatronics, 2012.

[7] Hu Ying, Zhang Xizheng, Wang Yao Nan, "Design of Vehicle Stability Control of Distributed Driven Electric Vehicle Based on Optimal Torque Allocation", Proceedings of The $33^{\text {rd }}$ Chinese Control Conference, 2014.

[8] Jia Sheng Hu and Dejun Yin, "MTTE based Motion Stabilization Control for In Wheel Motor Electric Vehicles", SICE Annual Conference, 2011.

[9] Johan Scholliers, dkk, "Depelopment and Application of an Integrated Evaluation Framework for Preventive Safety Aplications", IEEE Transaction on Intelligent Transportation Systems, Vol. 12, No. 1, March 2011.

[10] Kiencke U. and Nielsen L., “Automotive Control Systems”, Springer, 2005.

[11] Luigi Glielmo, "Active Safety Control for Automobile”, The Impact of Control Technology, Italy, 2011.

[12] M. Azman, P. D. King, and H. Rahnejat, "Combined bounce, Pitch, and Roll Dynamics of Vehicles Negotiating Single Speed Bump Events", Professional Engineering Publishing/IMECHE, 2014. DOI:10.1243/1464419JMBD55.

[13] Marco Gubitosa, "Chasis, Design, and Active Control Systems for Vehicle Dynamics and Active Safety”, Siemens Project Bussiness, Belgum, 2013.

[14] Martino Raffaele, "Modelling and simulation of the dynamic behavior of the automobile", Thesis of degree, faculty of engineering, Universita degli studi di salerno, 2012.

[15] Michael K. B., Amir Khajepour, "Optimal Control Allocation for Coordinated Suspension Control", IEEE American Control Conference, 2014.

[16] Nigam Chandra Parida, Saumyendu Raha and Anad Ramani, "Rollover Preventive Force Synthesis at Active Suspensions in a Vehicle Performing a Severe Maneuver with Wheels Lifted Off', IEEE Transactions on Intelligent Transportation Systems, Vol. 15, No.6, December, 2014.

[17] Pacejka H. B., "Tyre and Vehicle Dynamics", Elsevier Science, 2005.

[18] Rajamani R., "Vehicle Dynamics and Control", Springer Verlag, 2006.

[19] Sangoh Han, Kunsoo Huh, "Monitoring System Design for Lateral Vehicle Motion", IEEE Transactions on Vehicular Technology, Vol. 60, No. 4, May 2011.

[20] Shinsuke Sato and Hiroshi Fujimoto, "Proposal of Pitching Control Method Based on Slip Ratio Control for Electric Vehicle”, IEEE, 2008.

[21] T. D. Murphey, J. W. Burdick, "A Controllability Test and Motion Planning Primitives for Overconstrained Vehicles", Proceedings of The IEEE International Conference on Robotics Automation, 2001. 
[22] Tong Liang, Zhang Beibei, "Study on Experiment Platform of Integrated Steering and Braking Control for Vehicle Active Safety System”, IEEE, 2010.

[23] Wei-Song Lin, Tao-En Tang, "Active Safety Diagnosis of Brake-by-Wire Systems with Unscented Kalman Filter", IEEE, 2010.

[24] WONG, J. Y., "Theory of Ground Vehicles". John Wiley \& Sons Ltd, 3rd Edition, 2001.

[25] WU Xinye, "Research on Vehicle Rollover and Control", IEEE, 2010 